\title{
Effects of thermal stress on key processes driving coral-population dynamics
}

\author{
Lynnette Roth $^{1, *}$, Semen Koksal $^{2}$, Robert van Woesik ${ }^{1}$ \\ ${ }^{1}$ Department of Biological Sciences, and ${ }^{2}$ Department of Mathematical Sciences; Florida Institute of Technology, \\ 150 West University Boulevard, Melbourne, Florida 32901, USA
}

\begin{abstract}
A primary goal of ecology is to understand population dynamics by quantifying key processes that regulate population densities through time. Change to any one process may alter the population trajectory, its genetic constitution, and its size-frequency distribution. This study sought to quantify which of the 5 processes - (1) recruitment, (2) post-settlement mortality, (3) growth, (4) partial mortality and (5) total colony mortality — most influenced corymbose Acropora coral-population dynamics on reefs in southern Japan. Here we tracked coral reef colonies at a windward site and a leeward site from 1996 to 2001 through a thermal anomaly $\left(+1.8^{\circ} \mathrm{C}\right.$ in 1998). We were particularly interested in examining which of those processes had the largest effect on population dynamics. To predict size-frequency distributions, we constructed a system of nonlinear differential equations that included those 5 processes. Recruitment at the windward site remained consistent through time, whereas the leeward site had more variable recruitment rates at all depths, and showed a considerable decrease after the 1998 thermal anomaly that remained suppressed for many years. At all depths, the proportion of colonies transitioning to a larger size class was higher during the thermal anomaly than in other years. Partial mortality was generally highest on 20 to $30 \mathrm{~cm}$ length colonies, but was not a good indicator of thermal stress. Total colony mortality was most evident for the smallest and largest corymbose Acropora colonies during the thermal anomaly, effectively narrowing the size-frequency distributions. Sensitivity analyses revealed that total colony mortality had the largest effect on coral-population growth rate $(\lambda)$, followed by post-settlement mortality and recruitment. Quantifying the population processes that lead to state changes is a prerequisite for understanding reef dynamics in a rapidly warming ocean.
\end{abstract}

KEY WORDS: Sensitivity · Size-frequency distribution · Modeling $\cdot$ Bleaching $\cdot$ Temperature

\section{INTRODUCTION}

Coral-population dynamics are influenced by population processes that act on individual colonies at all life history stages from differential recruitment and survival (Birkeland 1977, Vermeij \& Sandin 2008) through to senescence (Rinkevich \& Loya 1986, Bak \& Meesters 1999). Still, we know little about population processes and how they vary spatially, seasonally and under different environmental conditions. We understand even less about differential weightings and sensitivities of populations to slight process changes and the repercussions of those changes on subsequent population trajectories. In a time of rapid climate change (IPCC 2007), it is pertinent to quantify population processes to determine which of them are most sensitive to environmental shifts and examine those processes within the context of population vulnerability to phase shifts (Scheffer \& Carpenter 2003, van Nes \& Scheffer 2007, Guttal \& Jayaprakash 2008).

This study investigated 5 coral-population processes: (1) recruitment (newly settled juveniles), (2) postsettlement mortality (death of newly settled recruits), (3) colony growth (transition into a larger size class), 
(4) partial mortality (transition into a smaller size class) and (5) total colony mortality (loss of entire colonies from the system), and asked whether some of these processes are more vital to population sustenance than others. We also assessed process influence, or sensitivity, and whether sensitivity changes after a disturbance in accordance with habitat, depth and across time. For example, sexual reproduction and recruitment may be critical in a rapidly changing environment, but may be less critical under steady state conditions (Lasker 1990, Edmunds 1994, Lasker \& Coffroth 1999, Pechenik 1999), especially for clonal organisms such as corals. Under stable environments, coral colony fragmentation may maintain population densities for decades or even centuries at any given locality (Babcock 1991). Yet under thermal stress, cloning is less effective and sexual reproduction and the production of freeswimming planulae might be a better survival option (van Woesik 2009).

Differential larval supply, or 'supply-side ecology', dominated the literature through the 1980s and 1990s (Keough \& Downes 1982, Underwood \& Fairweather 1989, Underwood \& Keough 2001) and was thought to be the primary determinant of most marine population trajectories. Some researchers even suggested that sexual recruitment was the most critical process driving population change (Doherty \& Fowler 1994), while others showed that differential mortality was more consequential (Tanner et al. 1996). These arguments have recently re-emerged as investigations of assemblage rules and niches on coral reefs (Pandolfi 2002, Karlson et al. 2004, Connolly et al. 2005, Hoogenboom \& Connolly 2009). Scheffer \& van Nes (2006) convincingly argued that multiple species can coexist at any one niche-habitat, and one species per niche may no longer apply (Hutchinson 1978, Holt 2009). Multiple-species niches agree with Hubbell's (1997) assumptions of neutrality, but for coral reefs neutrality may be only relevant in benign habitats where selective pressures are weak (van Woesik 2002, Dornelas et al. 2006).

There is a certain urgency to identify the primary selective forces that drive population dynamics, and to determine which population processes are necessary or vital to maintain coral-populations through time. Without understanding the vital population processes, we will merely continue to measure changes in reef states (i.e. coral cover) without understanding what processes have caused the changes. Therefore, quantifying the processes that maintain coral-populations and those that lead to the state changes is a prerequisite for understanding regime shifts and reef dynamics, particularly at a time of ocean warming (Webster et al. 2005).

In 1998, the reefs adjacent to Okinawa, Japan, experienced temperatures of $\sim 3^{\circ} \mathrm{C}$ above the seasonal aver- age that caused widespread coral bleaching, extensive coral mortality and compositional shifts in coral assemblages (Loya et al. 2001). Aka Jima, which is $30 \mathrm{~km}$ west of Okinawa (Fig. 1), experienced $1.8^{\circ} \mathrm{C}$ above the seasonal average water temperature (Fig. 2). We hypothesized that (1) the $1.8^{\circ} \mathrm{C}$ thermal anomaly on Aka Jima shifted the size-frequency distribution of the corals in the same right-skewed direction as the $3^{\circ} \mathrm{C}$ temperature anomaly, and (2) the thermal anomaly affected the sensitivities of the processes differently than in the nonthermal anomaly years. Based on findings by Tanner et al. (1994, 1996), we also hypothesized that (3) mortality rates were most influential throughout the study period, and further hypothesized that (4) recruitment was reduced after the thermal anomaly. Our main objectives were to (1) assess the

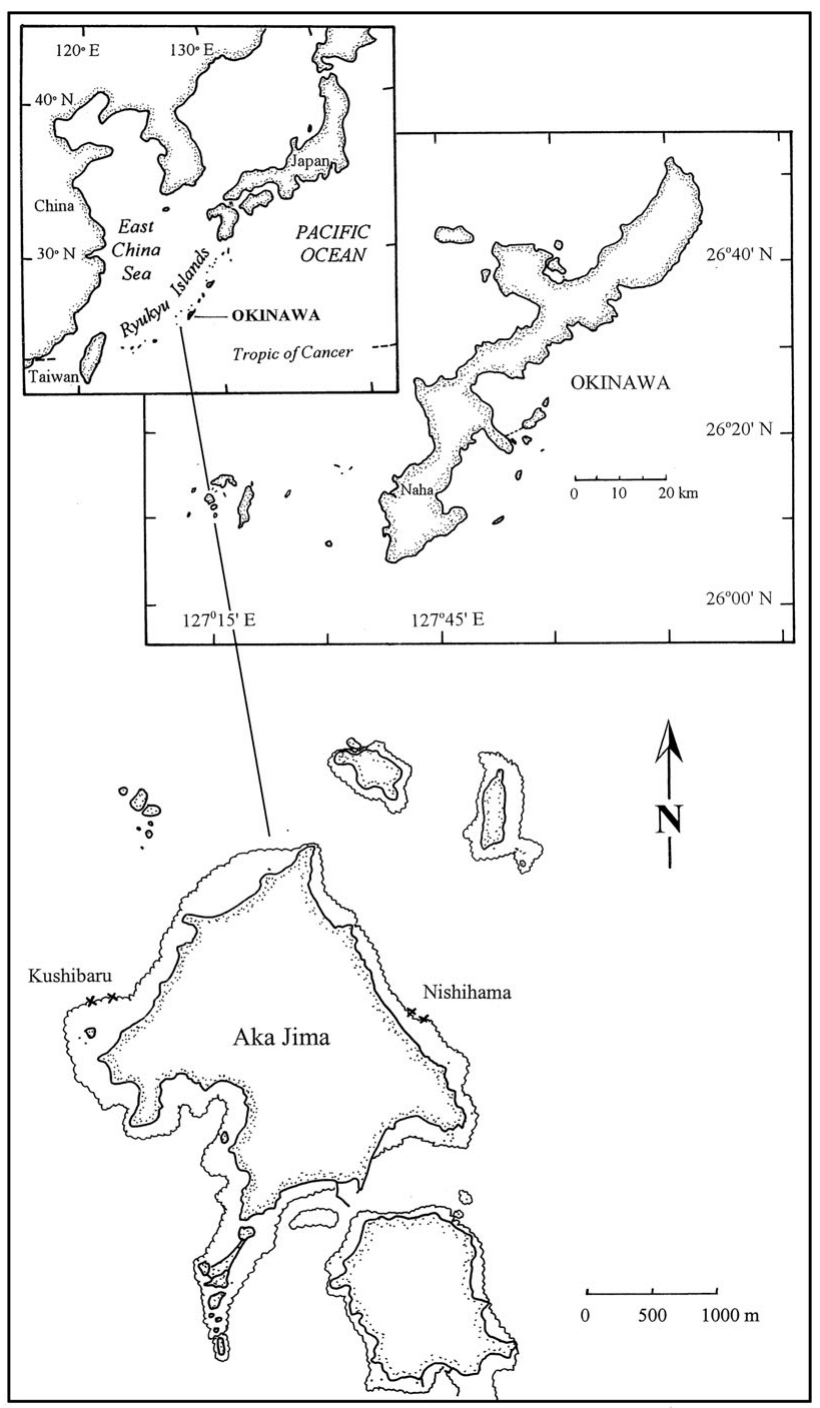

Fig. 1. Study sites on the windward (Kushibaru) and leeward (Nishihama) reefs of Aka Jima, southern Japan. Insets show location of study area near Okinawa 
dynamics of coral-populations in southern Japan (Fig. 1) by defining the population processes that most influenced coral-population change (Fig. 3), (2) examine the process sensitivities over yearly transitions, which included a positive thermal anomaly, (3) assess the interrelationship between population processes and state variables and (4) input the vital processes into a novel model that was validated against population trajectories through time. The model allowed us to predict size-frequency distributions into the future under different thermal stress scenarios. We note that the information and projected models can be used as benchmarks by which to judge coral-population dynamics in the Pacific Ocean, considering that the

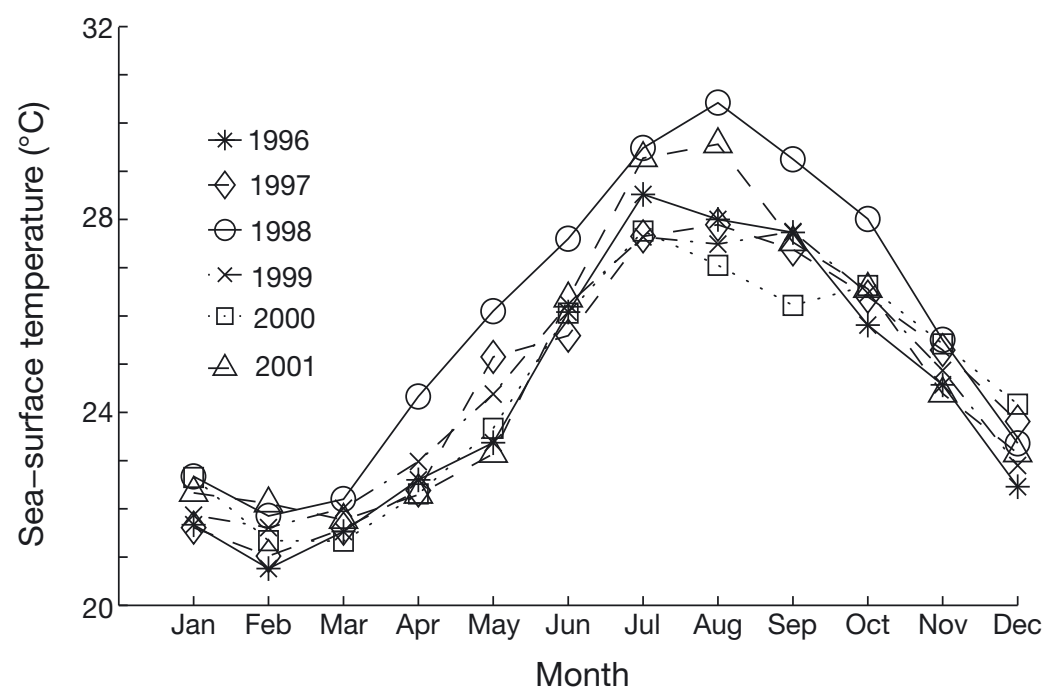

Fig. 2. Mean monthly sea surface temperatures at Aka Jima during the study period, 1996 to 2001

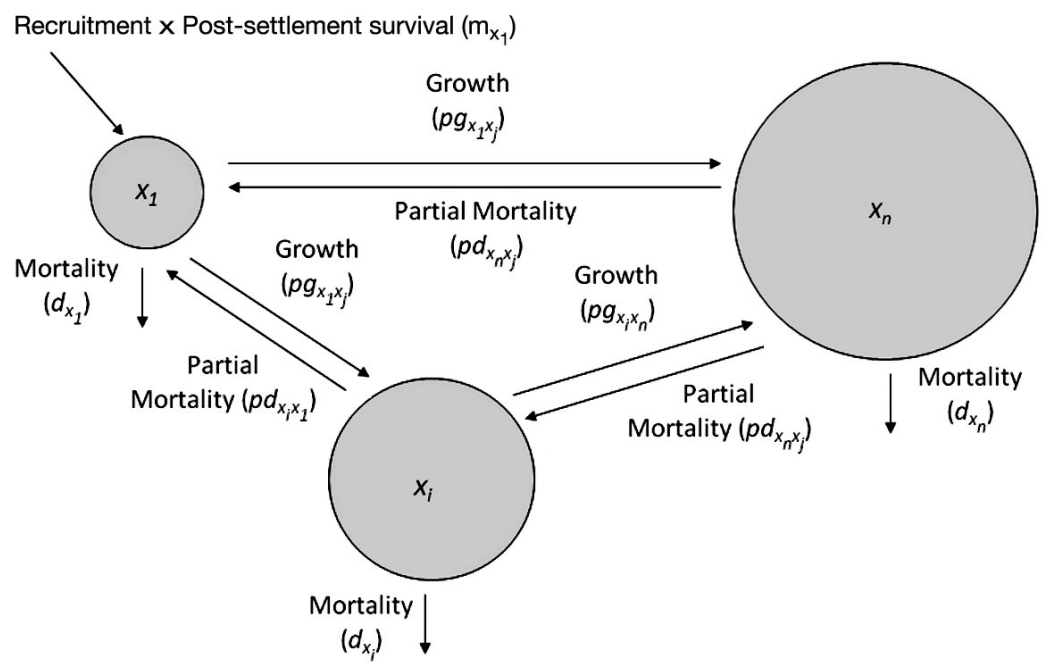

Fig. 3. Schematic illustration of 3 representative coral colony size classes and the major processes that govern changes in size-frequency distributions coral community composition in the southern islands of Japan overlaps $95 \%$ with that of the Great Barrier Reef (Veron 1992).

\section{MATERIALS AND METHODS}

Study sites and sampling. Field work was conducted between 1996 and 2001 at Aka Jima, southern Japan (Fig. 1). The study area was selected because of the remoteness of Aka Jima, which supports only 220 inhabitants, and because of the high coral diversity and coral coverage $(>60 \%)$. Two study sites were selected: Nishihama (leeward), and Kushibaru (windward). Both sites supported 2 haphazardly selected stations. Within each station, a $2 \times 2 \mathrm{~m}$ quadrat was haphazardly chosen and subsequently fixed with concrete nails at each of 3 depths ( 0 to 1,3 to 4 and 6 to $7 \mathrm{~m}$ ) and photographed annually between August and November. Recruitment was measured in the field annually using a $1 \mathrm{~m}^{2}$ quadrat partitioned into $100 \mathrm{~cm}^{2}$ subsections within the established $2 \times 2$ m quadrats. All newly settled coral colonies (from 1 to $20 \mathrm{~mm}$ ) were measured and identified to the highest possible taxonomic resolution. Counts of Acropora recruits did not include fragments from larger adult colonies, but did include all Acropora growth forms ( $<20 \mathrm{~mm})$. This study focused on corymbose Acropora, which are colonies with determinant growth forms that are radially symmetrical (essentially pillow shaped), with horizontal branches originating from around the central growing point and ending in the same plane (Wallace 1999).

From the photographs, each corymbose Acropora colony was numbered, measured (maximum length) and tracked through time. Maximum colony length was used in this study because (1) field studies routinely use maximum colony length for size-frequency calculations, and (2) we wanted our sizefrequency model to be easily translated to a variety of field studies that do not use projected surface area. Only colonies that had their centers located within the quadrats were tracked (Zvuloni et al. 2008). This study focused on corymbose Acropora colonies primarily because of their shallow dominance in the western 
Pacific Ocean, and their sensitivity to environmental disturbances (van Woesik \& Done 1997). The colonies consisted mainly of Acropora nasuta with a few A. digitifera and A. gemmifera colonies; these colonies were combined as the functional group 'corymbose Acropora', because of similar life history strategies and growth rates, and used in a population model (as in Done 1988, Tanner et al. 1994, 1996). Mortality was assumed if the colony had no living tissue in the subsequent photograph, and partial mortality was categorized as any colony that was smaller in a subsequent time period. Percentage coral cover was calculated by means of the point-intercept method (i.e. placing 100 points per $\mathrm{m}^{2}$ evenly on each quadrat using coral point count with Excel extensions (CPCe $3.4^{\circledR}$ ). The size of each coral colony was calculated with the following equation:

$$
\frac{D_{\mathrm{mc}}}{D_{\mathrm{mt}}}=\frac{D_{\mathrm{c}}}{D_{\mathrm{t}}}
$$

where $D_{\mathrm{mc}}$ is the measured colony length, $D_{\mathrm{mt}}$ is the measured scale in the photo, $D_{\mathrm{t}}$ is the actual length of tape placed on the quadrat (using $10 \mathrm{~cm}$ intervals for scaling) and $D_{\mathrm{c}}$ is the calculated colony size. The total maximum error related to estimated coral colony size was calculated with the absolute error form of Eq. (1).

Data analysis. Corymbose Acropora colonies from adjacent stations were pooled within each depth to increase sampling densities after Mann-Whitney $U$-test analyses showed no significant differences in the initial measurements between stations. Each coral colony was placed into one of 7 size-class bins based on maximum length $(0.1$ to $10,10.1$ to $20,20.1$ to $30,30.1$ to 40 , 40.1 to $50,50.1$ to 60 and $>60 \mathrm{~cm}$ ). This separation allowed for an adequate number of colonies within each size class to discern a distribution, while taking into account approximate colony growth rates $(\sim 10 \mathrm{~cm}$ $\mathrm{yr}^{-1}$ ). We tested the goodness of fit of the observed size-frequency distributions to the normal (Gaussian), chi-square and log-normal distributions.

To quantify growth and partial mortality effects, a data set was created of all the colony size differences for each yearly transition. Colonies that did not exist throughout the entire study period were not considered for this data set. A nonparametric Scheirer-RayHare (S-R-H) extension of the Kruskal-Wallis test was performed on these data (because the assumptions of normality were violated) to test for differences in overall colony growth (negative or positive) for each population through time (Scheirer et al. 1976). A nonparametric Friedman's repeated measures comparisons test was performed on the recruitment data, which were means derived for each station (to avoid pseudoreplication) and stratified by depth, to test for differences in recruitment between sites through time.
The coral model. The primary objective of this study was to incorporate the key population processes that influenced corymbose Acropora population dynamics into a generic model (Fig. 3). The processes included: (1) recruitment, (2) post-settlement mortality, (3) growth, (4) partial mortality, (5) fragmentation and (6) total colony mortality, within a space limitation framework to predict coral-population density and size-frequency distribution. We constructed a system of nonlinear differential equations that governed the dynamics of coral colony size classes, $x_{i}$ for $i=1, \ldots, n$, through time, and used the empirical data as input parameter values. Here, $x_{1}$ and $x_{n}$ denote the number of colonies within the smallest and largest coral colony size classes, respectively. This model is defined as:

$$
\begin{aligned}
\frac{\mathrm{d} x_{1}}{\mathrm{~d} t}= & m_{x_{1}} K+\sum_{j=2}^{n} p d_{x_{j} x_{1}} F_{x_{j} x_{1}} x_{j}-\left(d_{x_{1}}+K \sum_{j=2}^{n} p g_{x_{1} x_{j}}\right) x_{1} \\
\frac{\mathrm{d} x_{i}}{\mathrm{~d} t}= & K \sum_{j=1}^{i-1} p g_{x_{j} x_{i} x_{j}}+\sum_{j=i+1}^{n} p d_{x_{j} x_{i}} F_{x_{j} x_{i}} x_{j}- \\
& \left(d_{x_{i}}+\sum_{j=1}^{i-1} p d_{x_{i} x_{j}} F_{x_{i} x_{j}}+K \sum_{j=i+1}^{n-1} p g_{x_{i} x_{j}}\right) x_{i} \\
& i=2,3, \ldots, n-1 \\
\frac{\mathrm{d} x_{n}}{\mathrm{~d} t}= & K \sum_{j=1}^{n-1} p g_{x_{j} x_{n}} x_{j}-\left(d_{x_{n}}+\sum_{j=1}^{n-1} p d_{x_{n} x_{j}} F_{x_{n} x_{j}}\right) x_{n}
\end{aligned}
$$

where $m_{x_{1}}$ is the number of surviving recruits that enter the first size class, $x_{1}, d_{x}$ is the total mortality rate of each class size, $x_{i,} p d_{x_{j} x_{i}}$ is the transition rate into any smaller size class, from $x_{j}$ to $x_{i}$, representing partial mortality, $F_{X_{j} x_{i}}$ is the number of coral fragments generated through partial mortality, and $p g_{x_{i} x_{j}}$ is the transition rate into any larger size class, from $x_{i}$ to $x_{j}$, representing growth. The proportion of space available for recruitment and growth, $K$, is a function, $f\left(x_{1}, x_{2}, \ldots, x_{n}\right)$, that changes dynamically through time based on the abundances of each size class, $x_{i}$ terms, which in turn are limited by available space. Space limitation was introduced, and took the place of a competition term to prevent unrealistic unlimited growth of these populations. Recruitment was modeled as a Poisson process, which is a discrete random process in which events (recruits) occur independently of each other (Eq. 3). This submodel was parameterized according to the mean number of recruits observed in the field. The Poisson distribution was defined by the following equation:

$$
y=f(x \mid \mu)=\frac{\mu^{x} e^{-\mu}}{x !}
$$

where $\mu$ is the sample mean number of recruits observed in the field. For each iteration, an annual recruitment number was randomly selected from the fitted Poisson distribution. Post-settlement mortality 
was estimated by using the difference between the number of new colonies and recruits between $t$ and $t+1$ and multiplied by the randomly selected number of recruits from the Poisson distribution to give the number of new colonies for each iteration. The number of colony fragments was calculated with a limited binomial distribution, as a sum of Bernoulli random variables defined by the following equation:

where

$$
y=f(x \mid n, p)=\left(\begin{array}{l}
n \\
x
\end{array}\right) p^{x} q^{(n-x)}
$$

$$
\left(\begin{array}{l}
n \\
x
\end{array}\right)=\frac{n !}{x !(n-x) !}
$$

and where $q=1-p$. The resulting value for $y$ is the probability of observing $x$ number of fission events in $n$ individual coral colonies, where the probability of fission in any given colony is $p$. The values for $n$ and $p$ were kept constant throughout because few corymbose Acropora colonies were observed splitting, a trait more characteristic of Porites species. We defined the proportion of space available for recruitment and growth, $K$, as a function of all $x_{i}$ values where:

$$
K=f\left(x_{1}, x_{2}, \ldots, x_{n}\right)=1-\left[\left(C-A_{c}\right)+\sum_{i=1}^{n} C_{i} x_{i}\right]
$$

and where $C$ is the total proportional cover of all the corals present in each quadrat, and $A_{\mathrm{c}}$ is the total proportional cover of all corymbose Acropora colonies at the initial time step in each quadrat. The constant, $C_{i}$, is determined by:

$$
C_{i}=\frac{\overline{a_{x_{i}}}}{T}, i=1, \ldots, n
$$

where $\overline{a_{x_{i}}}$ is the average area occupied by a colony in the size class $x_{i}$ and $T$ is the total available sample space (i.e. quadrat surface area). Hence, the summation term in Eq. (6) estimates the density of corymbose Acropora in each size class, at each time step, allowing the corymbose Acropora density to vary through time. To predict population structural changes through time, we numerically solved Eqs. (2), (4) \& (6) by means of the fourth-order Runge-Kutta methods (Shampine \& Reichelt 1997).

Model simulations. A series of simulations were run to validate the model and then determine which set of population processes best described the population in 2000. To begin, 2 simulations were analyzed: (Simulation 1) one with rates from 1996 to 1997, which projected the population under nonthermal stress years, and (Simulation 2) another with rates from 1998 to 1999, which projected the population under repeated thermal anomaly conditions for every year in the time series trajectory (initial abundances are provided in
Table S1 and transition matrices are presented in Tables S2 to S9 in Supplement 1 available at www.intres.com/articles/suppl/m411p073_supp.pdf). Two further simulations were undertaken with the initial 1996 to 1997 colony abundances and transition rates. The third simulation (Simulation 3) added a 1 yr thermal anomaly event (1998 to 1999) (1 disturbance year), and the fourth simulation (Simulation 4) added a 2 yr thermal anomaly event ( 2 disturbance years). The projected (simulation) abundances were extracted for each size class for the year 2000 and compared with the actual field data by means of a KolmogorovSmirnov (K-S) test; the K-S test was coded in MATLAB ${ }^{\circledR}$ version 6.5 to allow direct comparisons of each size class, without rearranging the data, to determine which of the 4 modeled size-frequency distributions best fit the empirical data. A goodness-of-fit analysis, that used sum of squared differences, was used to determine the variance around the 2 (expected and observed) distributions, thereby determining the bestfit model for each site and depth.

Once the best-fit model was established, 3 different projection simulations were analyzed for trends under different disturbance regimes. Each simulation used rates and initial abundances from 1996 to 1997 and a (1 yr) thermal anomaly (using 1998 to 1999 data) every 5 yr (Simulation 5), a (1 yr) thermal anomaly every $10 \mathrm{yr}$ (Simulation 6) and a simulation with a (1 yr) thermal anomaly every 15 yr (Simulation 7 ) until the year 2021. All models were run with MATLAB ${ }^{\circledR}$ version 6.5 (and are available upon request).

Sensitivity analysis. Stage-structured Lefkovitch matrices (Lefkovitch 1965) were constructed for corymbose Acropora populations at each site for all depths, for each time transition. Each matrix has $S$ latent roots (eigenvalues) $\lambda_{i}$, each with a stable column vector (eigenvector) $v_{i}$, such that:

$$
M_{t} v_{i}=\lambda_{i} v_{i} \quad(i=1,2, \ldots, s)
$$

The dominant eigenvalue is an indicator of the rate at which the population structure approaches the structure dictated by the dominant eigenvector. Therefore, the magnitudes of the dominant eigenvalues $(\lambda)$ were examined through a series of sensitivity manipulations that assessed which stage transition most affected population dynamics. More specifically, sensitivity $(S)$ of each individual size class was determined by examining the dominant eigenvalue $(\lambda)$ with respect to the change in each element of $M_{t}\left(m_{i j}\right)$ (Caswell 2001), by means of the following equation:

$$
S=\left(\frac{\partial \lambda}{\partial m_{i j}}\right)
$$

We examined the sensitivity of each population process (i.e. recruitment, post-settlement mortality, 
growth, partial mortality and total mortality) by increasing and decreasing each value by 10 and $20 \%$ for each time step (using Eq. 2).

\section{RESULTS}

\section{Size-frequency distributions}

A log-normal distribution was the best fit distribution for the coral size-frequency data for both sites at all depths, for all years (Figs. 4 \& 5). We tested other distributions for goodness of fit, including normal (Gaussian) and chi-square distributions, and the log-normal distribution was consistently the best fit. Small corymbose Acropora colonies dominated most habitats whereas large colonies were more abundant on shallow reefs. There was an overall decline in colony abundance in 1999, a consequence of the 1998 thermal anomaly. The log-normal curves consistently shifted to

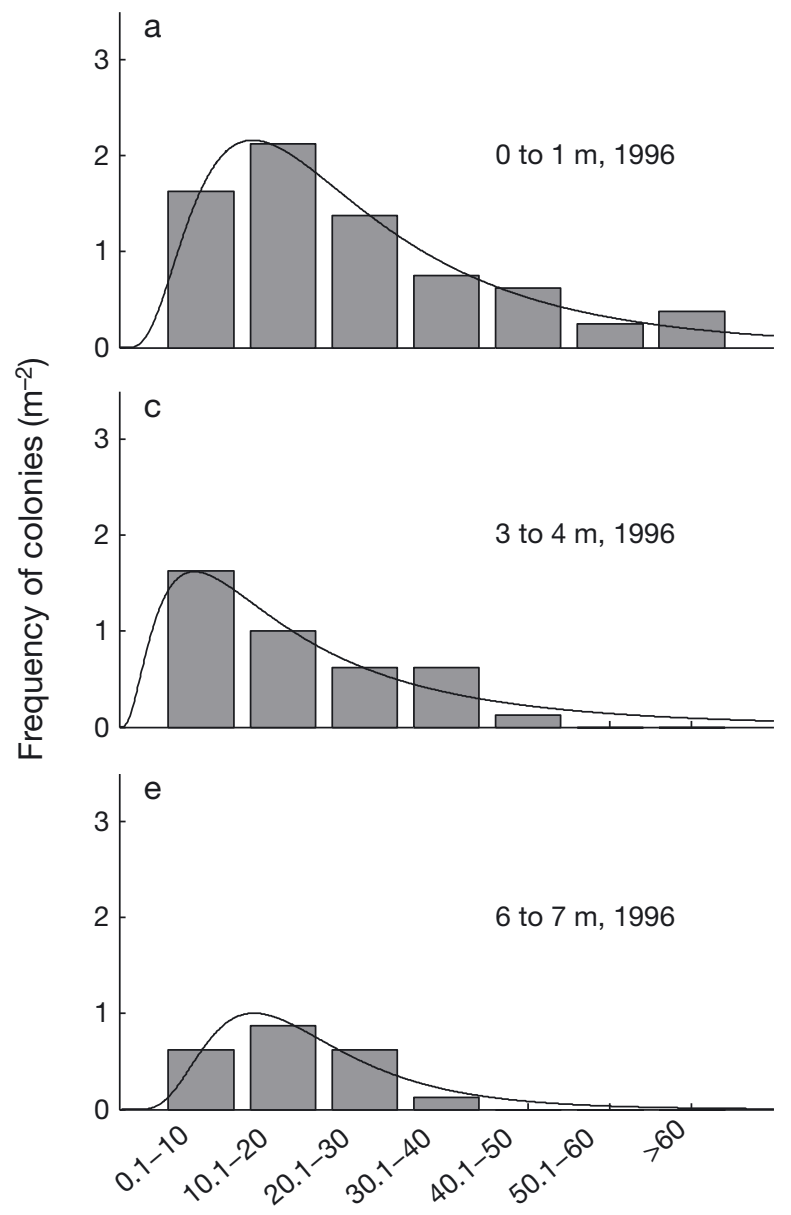

the right (i.e. the mean shifted toward larger colonies) after the thermal anomaly in 1998 (Figs. 4 \& 5, Table 1).

\section{Population processes}

Recruitment at Kushibaru averaged 2 to 4 corymbose Acropora $\mathrm{m}^{-2} \mathrm{yr}^{-1}$, and remained consistent through time (Fig. 6, Table 2). By contrast, Nishihama showed variable recruitment rates at all depths with a considerable decrease after the 1998 thermal anomaly; recruitment rates returned to prethermal anomaly rates in 2001, 3 yr later for the 0 to $1 \mathrm{~m}$ depth (Fig. 6). The Friedman's test revealed no significant differences in recruitment over time for either site; however, this test is very conservative given that we only had 2 stations per site. There was, however, a significant difference in Acropora recruitment through time at Nishihama when depth was ignored (Friedman's test: $\chi^{2}=$ 25.475, df =5, $\mathrm{p}=0.0001)$. Years 1999 and 2000 showed
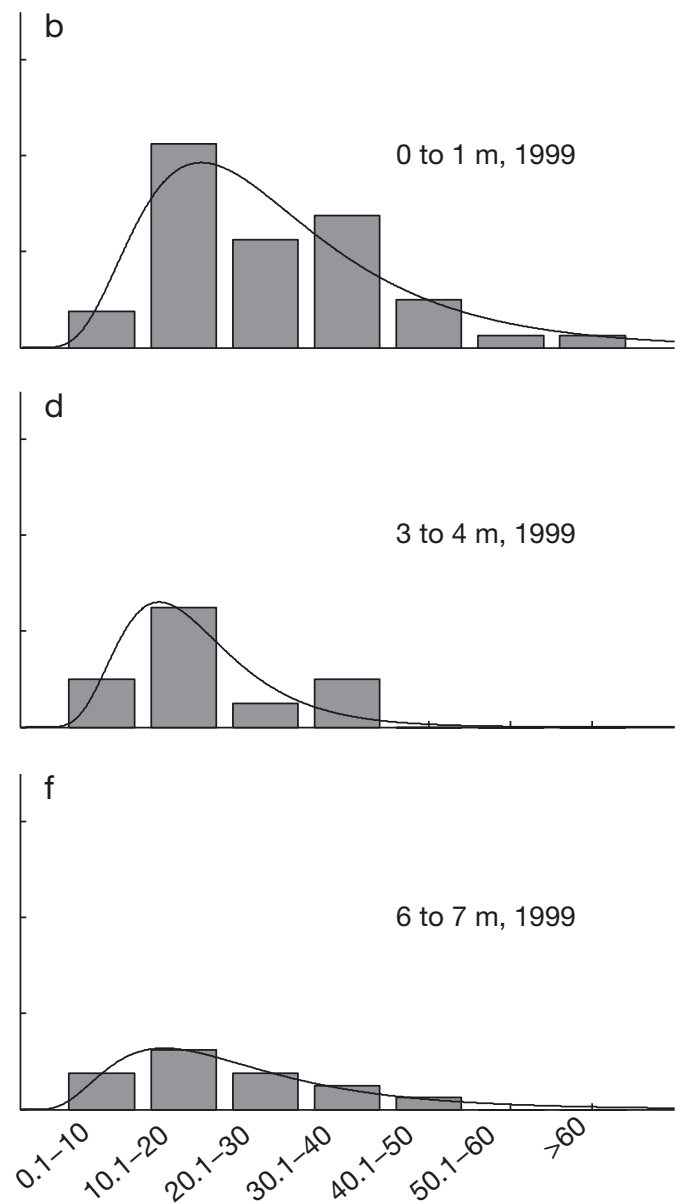

Size class $(\mathrm{cm})$

Fig. 4. Kushibaru. Size-frequency distributions of corymbose Acropora colonies and the best-fit log-normal distribution (a,c,e) before and (b,d,f) after the 1998 thermal anomaly over all depths 


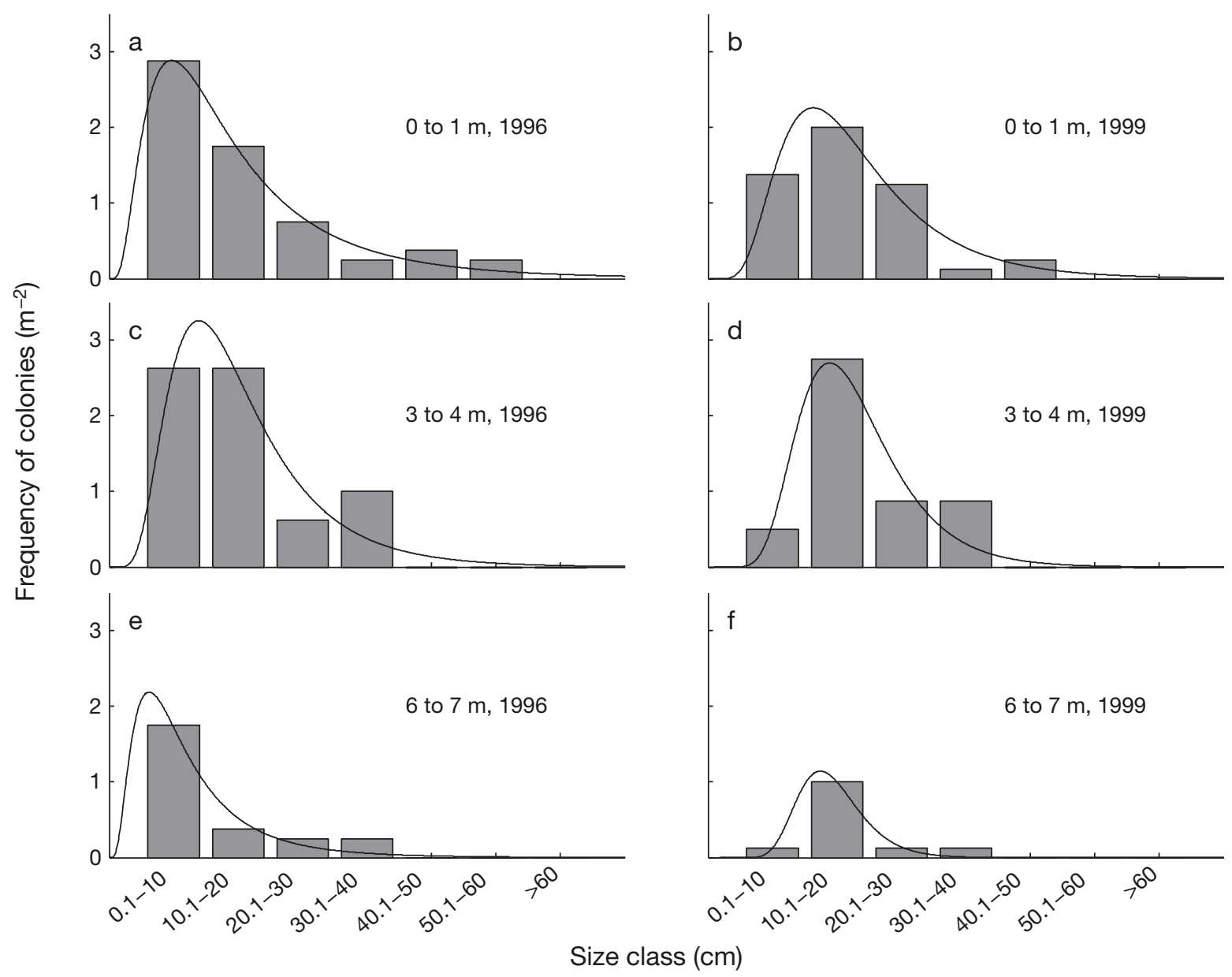

Fig. 5. Nishihama. Size-frequency distributions of corymbose Acropora colonies and the best-fit log-normal distribution (a,c,e) before and $(b, d, f)$ after the 1998 thermal anomaly over all depths

Table 1. Results from the log-normal curve fit comparing frequency of corymbose Acropora colonies by size class (Figs. 4 $\& 5) . \mu$ : mean; $\sigma$ variance

\begin{tabular}{|c|c|c|c|c|c|}
\hline Site & Depth (m) & Year & $\mu$ & $\sigma$ & $\mathrm{R}^{2}$ \\
\hline \multirow[t]{6}{*}{ Kushibaru } & \multirow[t]{2}{*}{1} & 1996 & 0.930 & 0.664 & 0.977 \\
\hline & & 1999 & 1.039 & 0.493 & 0.850 \\
\hline & \multirow[t]{2}{*}{3} & 1996 & 0.639 & 0.851 & 0.948 \\
\hline & & 1999 & 0.686 & 0.393 & 0.845 \\
\hline & \multirow[t]{2}{*}{6} & 1996 & 0.749 & 0.499 & 0.955 \\
\hline & & 1999 & 0.867 & 0.548 & 0.980 \\
\hline \multirow[t]{6}{*}{ Nishihama } & \multirow[t]{2}{*}{1} & 1996 & 0.470 & 0.710 & 0.988 \\
\hline & & 1999 & 0.726 & 0.485 & 0.963 \\
\hline & \multirow[t]{2}{*}{3} & 1996 & 0.588 & 0.509 & 0.930 \\
\hline & & 1999 & 0.765 & 0.361 & 0.925 \\
\hline & \multirow[t]{2}{*}{6} & 1996 & 0.000 & 0.693 & 0.971 \\
\hline & & 1999 & 0.626 & 0.265 & 0.982 \\
\hline
\end{tabular}

significant differences in recruitment from 1996, 1997 and 1998, while recruitment in 2001 was different from only 1996 and 1997 (Table 3).

The trend in post-settlement mortality rates was less obvious. In Kushibaru, rates remained high (>70\%) throughout the entire study period with no distinguishable difference among depths or during the thermal anomaly. Similar results were seen in Nishihama except that post-settlement mortality was very low in 1999 to 2000, one transition after the thermal anomaly at all 3 depths (Table 2). In all years, small colonies grew, on average, more frequently than did large colonies at both sites (Table 2). Most notably, during the thermal anomaly (1998 to 1999), the proportion of colonies transitioning to a larger size class was higher than in other years at all depths. Particularly obvious were the high growth rates of small colonies during the same year.

Partial mortality was generally higher for colonies with a maximum length between 20.1 and $30 \mathrm{~cm}$. The $\mathrm{S}-\mathrm{R}-\mathrm{H}$ test showed significant differences in overall 


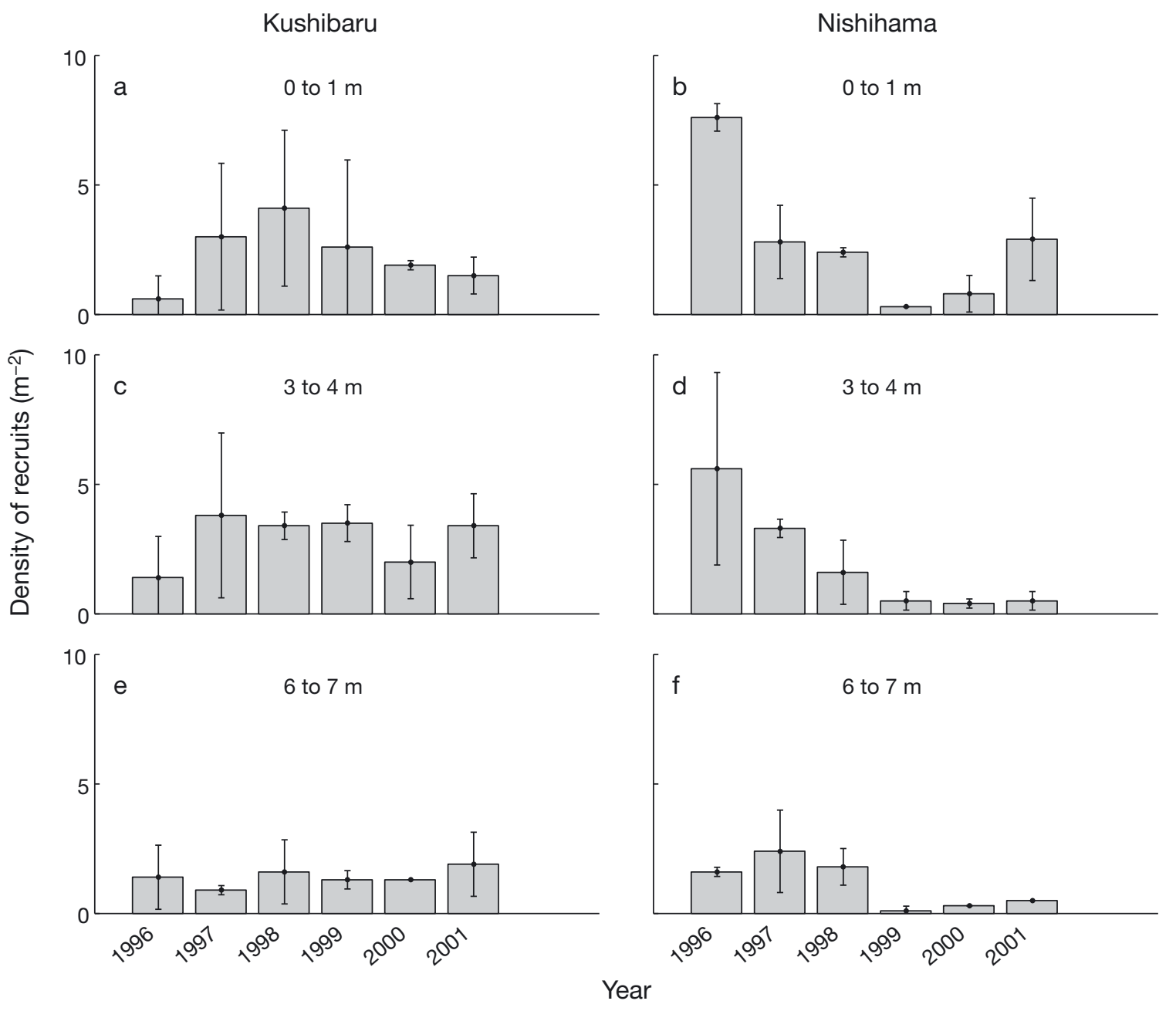

Fig. 6. Recruitment densities (mean \pm SD) of corymbose Acropora observed in the field for (a,c,e) Kushibaru and (b,d,f) Nishihama reefs through time, with data stratified by depth and averaged $\left(\right.$ per $\left.\mathrm{m}^{2}\right)$ within stations

colony growth between sites that were dependent on year. This difference was largely due to an increase in colony growth (in most size classes) for Nishihama populations from 1999 to 2000, whereas Kushibaru population's overall growth was slightly negative (i.e. a significant interaction term, Table 4). The thermal anomaly caused greatest loss of large and small colonies at all 3 depths; however, there was no discernable trend through time. Of the smallest colonies, between 0.1 and $10 \mathrm{~cm}, 50 \%$ grew into the next size class, $<10 \%$ stayed in the same size class and the rest died.

\section{The coral model}

At Kushibaru, only subtle differences were apparent in the size-frequency distributions at 0 to $1 \mathrm{~m}$ and in population response to different input (Lefkovitch) matrices (Fig. 7, Table 5); whereas at 3 and $6 \mathrm{~m}$, corymbose Acropora size-frequency distributions were most similar to the population trajectories predicted from the repeated thermal anomaly conditions (i.e. 1998 to 1999 data) for every year (Simulation 2). Populations at $1 \mathrm{~m}$ at Nishihama were also similar to trajectories from Simulation 2, whereas populations at 3 and $6 \mathrm{~m}$ were most similar to a 1 disturbance year input matrix (Simulation 3) (Fig. 7, Table 5). Consistent trends were observed under the 3 different disturbance regime simulations. As expected, the disturbance year always resulted in a decrease in population abundance for that given year, which was most evident at 0 to $1 \mathrm{~m}$ at Kushibaru, and 6 to $7 \mathrm{~m}$ at Nishihama (Fig. 8). Notably, all populations declined through time except at 6 to $7 \mathrm{~m}$ at Nishihama where the population slightly increased by 2021. We suspect that this anomalous 


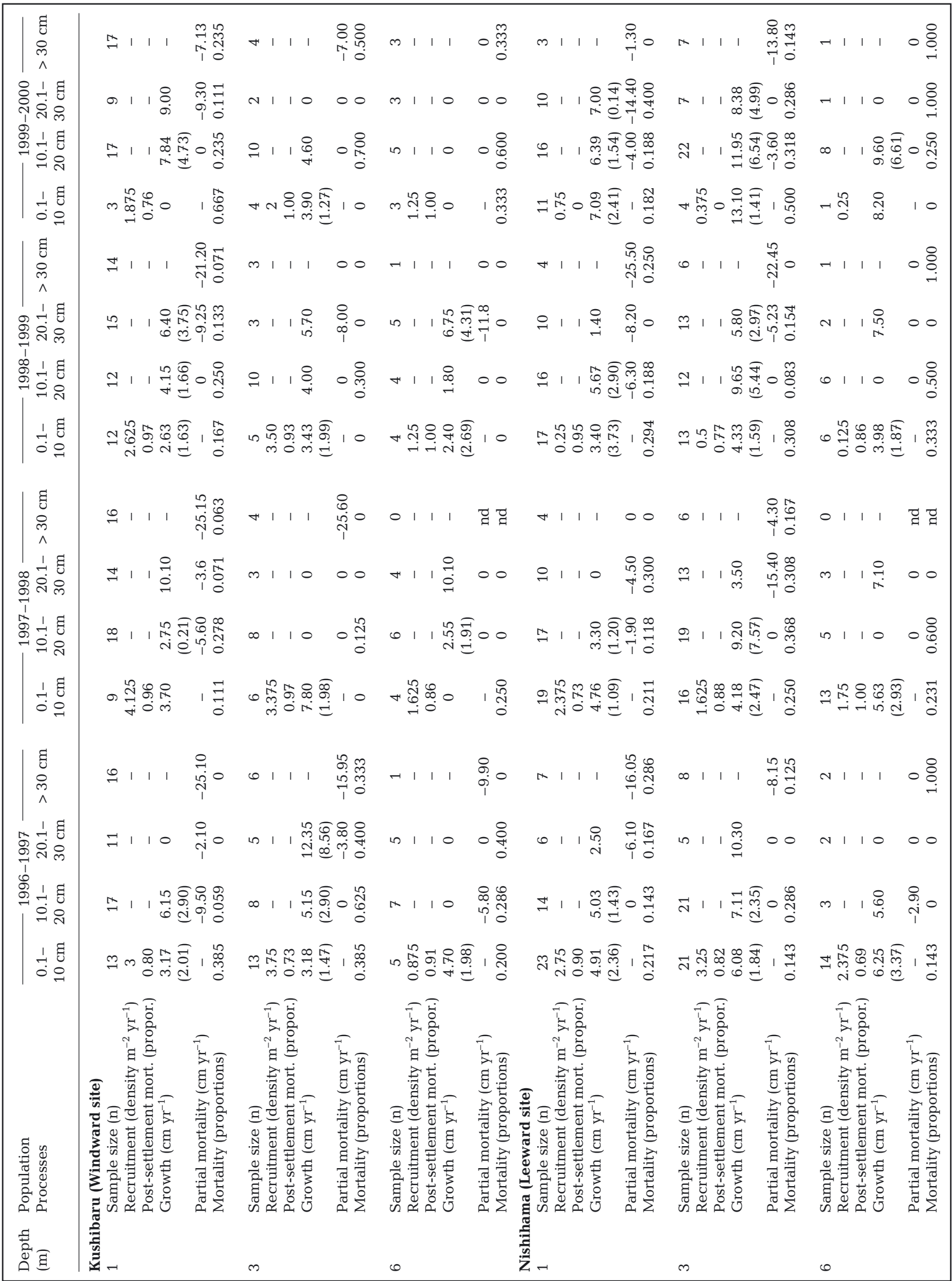


Table 3. Mann-Whitney $U$-test results comparing recruitment density over time; the significance level was adjusted with a Bonferroni correction for multiple comparisons tests $(\mathrm{n}=6$ for each test). ${ }^{*} \mathrm{p}<0.01$

\begin{tabular}{|ccccccc|}
\hline & \multicolumn{6}{c|}{$U$-statistic } \\
\cline { 2 - 6 } & \multirow{2}{*}{1996} & \multirow{2}{*}{1997} & 1998 & 1999 & 2000 & 2001 \\
\hline 1996 & \multirow{2}{*}{13.0} & 8.0 & $0^{*}$ & $0^{*}$ & $0^{*}$ \\
1997 & & & 8.5 & $0^{*}$ & $0.5^{*}$ & $0.5^{*}$ \\
1998 & & & & $0.5^{*}$ & $1.5^{*}$ & 2.0 \\
1999 & & & & & 13.0 & 8.5 \\
2000 & & & & & & 12.5 \\
2001 & & & & & & \\
\hline
\end{tabular}

increase was a consequence of low mortality rates in nonthermal stress years.

The effect of these simulations on predicted sizefrequency distributions $20 \mathrm{yr}$ into the future at 2016 was examined. The simulated size-frequency distribu-
Table 4. Results from the Scheirer-Ray-Hare extension of the Kruskal-Wallis test examining corymbose Acropora colony mortality across sites, depths and time. ${ }^{*} \mathrm{p}<0.05$

\begin{tabular}{|lccc|}
\hline Factor & df & $H$ & p-value \\
\hline Site & 1 & 6.95 & $<0.01^{*}$ \\
Depth & 2 & 0.67 & $<0.75$ \\
Year & 3 & 2.90 & $<0.50$ \\
Site $\times$ Depth & 2 & 0.67 & $<0.75$ \\
Site $\times$ Year & 3 & 7.93 & $<0.05^{*}$ \\
Depth $\times$ Year & 6 & 8.12 & $<0.25$ \\
Site $\times$ Depth $\times$ Year & 6 & 12.20 & $<0.10$ \\
\hline
\end{tabular}

tions showed a distribution narrowing because of partial and total mortality of large colonies, and growth and total mortality of the small colonies. These results were similar to the empirical data trends and were most obvious under high frequencies of thermal stress.

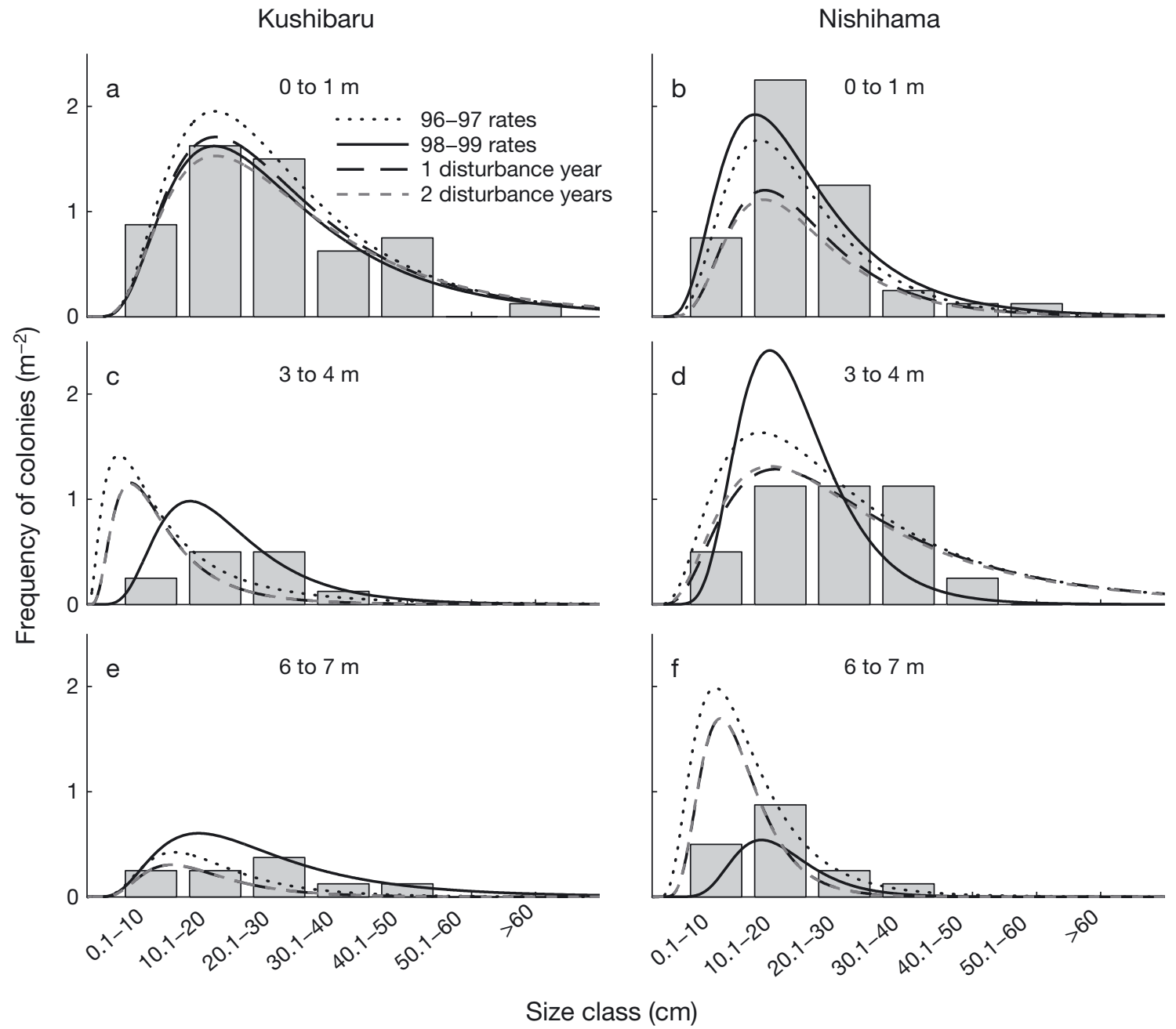

Fig. 7. Size-frequency distribution of empirical data for corymbose Acropora colonies from 2000 with model simulation results for 2000 fitted as curves for $(\mathrm{a}, \mathrm{c}, \mathrm{e})$ Kushibaru and $(\mathrm{b}, \mathrm{d}, \mathrm{f})$ Nishihama at all depths 
Table 5. Goodness-of-fit $\left(\mathrm{R}^{2}\right)$ values of Kolmogorov-Smirnov tests between the size-frequency distributions derived by the model simulations (1 to 4) compared with empirical size class data from 2000. ${ }^{*} \mathrm{p}<0.05$

\begin{tabular}{|lccccc|}
\hline Site & $\begin{array}{c}\text { Depth } \\
(\mathrm{m})\end{array}$ & $\begin{array}{c}\text { 1996-1997 } \\
\text { (Simulation 1) }\end{array}$ & $\begin{array}{c}\text { 1998-1999 } \\
\text { (Simulation 2) }\end{array}$ & $\begin{array}{c}\text { 1 disturbance year } \\
\text { (Simulation 3) }\end{array}$ & $\begin{array}{c}\text { 2 disturbance years } \\
\text { (Simulation 4) }\end{array}$ \\
\hline Kushibaru & 1 & 0.9072 & 0.8872 & 0.9087 & 0.8601 \\
(Windward site) & 3 & 0.5210 & 0.7361 & $0.4972^{*}$ & $0.4963^{*}$ \\
& 6 & 0.6068 & 0.6804 & 0.3837 & 0.3870 \\
Nishihama & 1 & 0.7858 & 0.8480 & 0.4449 & 0.3646 \\
(Leeward site) & 3 & 0.6762 & 0.6625 & 0.7390 & 0.6361 \\
& 6 & 0.5889 & 0.4687 & 0.6397 & \\
\hline
\end{tabular}

15-year scenario

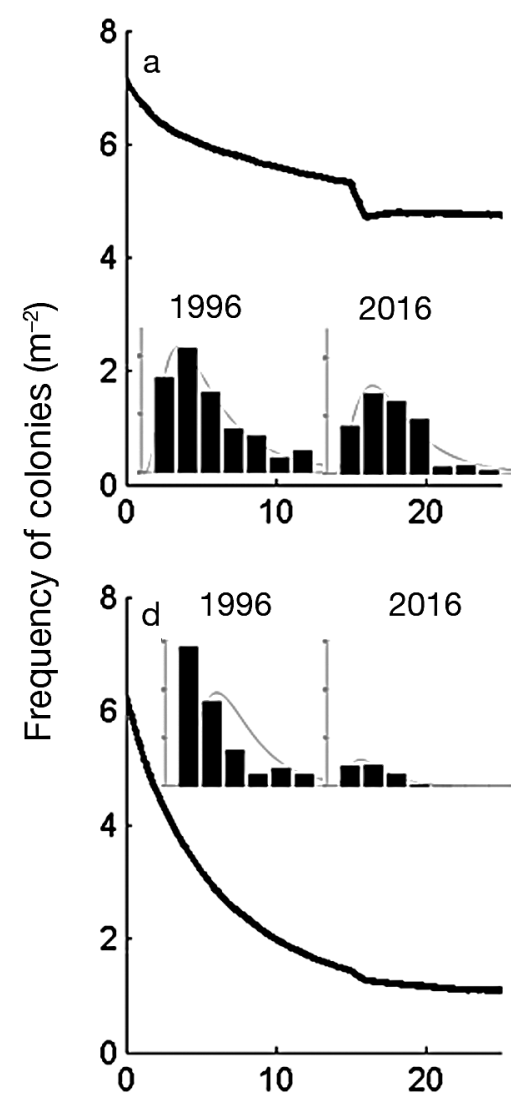

10-year scenario
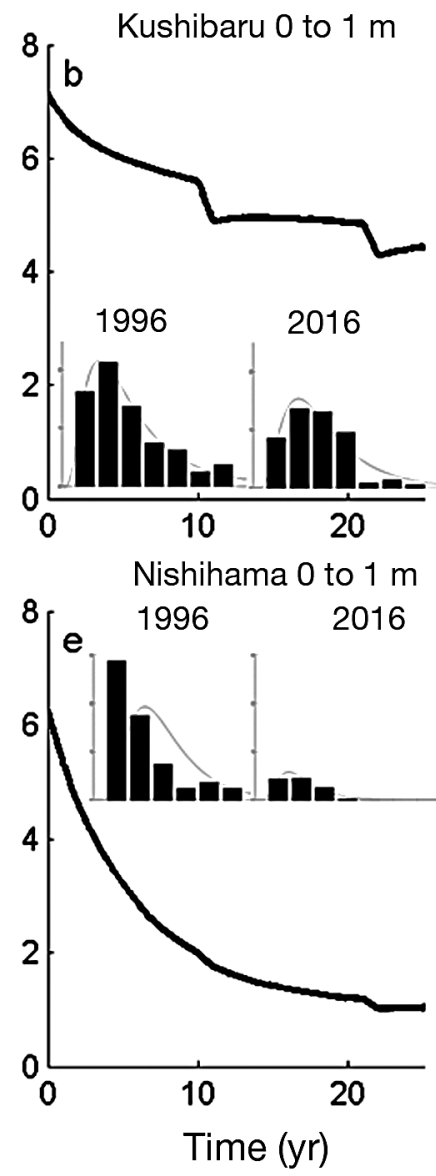

5-year scenario
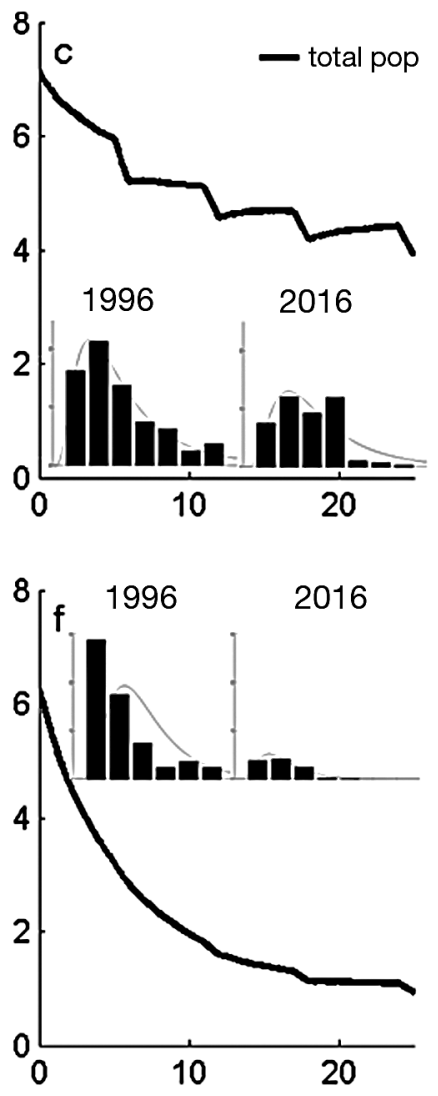

Fig. 8. Model simulations ( 5 to 7 ) that used rates and initial abundances from 1996-1997 and a thermal stress year (with data from 1998-1999) every 15, 10 and 5 yr for (a,b,c) Kushibaru, 0 to $1 \mathrm{~m}$, and (d,e,f) Nishihama, 0 to $1 \mathrm{~m}$. The insets show the original sizefrequency distribution for each site at 1996 (Year 0) compared with the predicted size-frequency distribution in 2016 (Year 20 ) for each simulation

\section{Sensitivity analysis}

Size-class sensitivity varied between sites, among depths and through time. Changes to corymbose Acropora colonies between 10 and $50 \mathrm{~cm}$ resulted in the greatest population variance at Kushibaru. In most cases, the greatest percentage change in population growth rate $(\lambda)$ resulted from a lack of sizeclass transition (i.e. no growth or partial mortality). The most sensitive size class at Nishihama was 20.1 to $30 \mathrm{~cm}$ for all depths, before and through the thermal anomaly, probably because of the high rates of 
partial mortality at that colony size. Differential mortality had the largest effect on coral-population dynamics $(\lambda)$ at both sites, at all depths, at all time periods, followed by recruitment and postsettlement mortality (Fig. 9).

\section{DISCUSSION}

A log-normal distribution provided the best fit for all the size-frequency distributions, indicating that the small corymbose Acropora colonies were numerically dominant through time. The 1998 thermal anomaly shifted the mean of each log-normal distribution to larger average colony lengths. Some potential causes
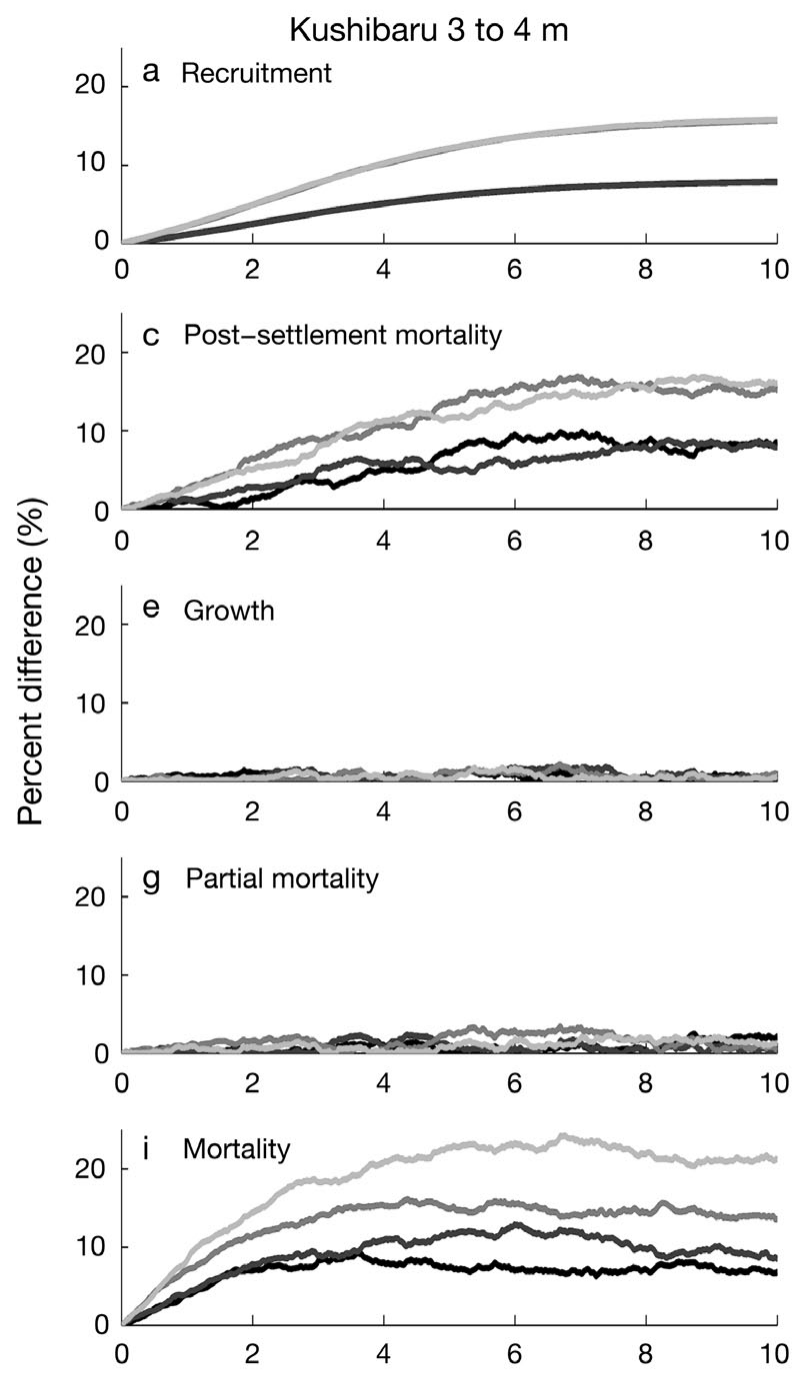

driving such size-frequency shifts included: (1) high mortality of small colonies, (2) rapid transition out of the smallest size classes because of rapid growth or (3) some combination of both factors 1 and 2 (Hughes \& Jackson 1985, Babcock 1991, Bak \& Meesters 1998, 1999). A closer examination of the data showed that transitions to and from size classes occurred more often than total colony mortality during the thermal anomaly. Indeed, compared with other years the thermal anomaly on Aka Jima increased average growth rates of corymbose Acropora colonies.

Previous studies found a higher overall survival of small colonies compared with large colonies through extreme thermal anomalies, which resulted in an extremely right-skewed distribution (Loya et al. 2001,
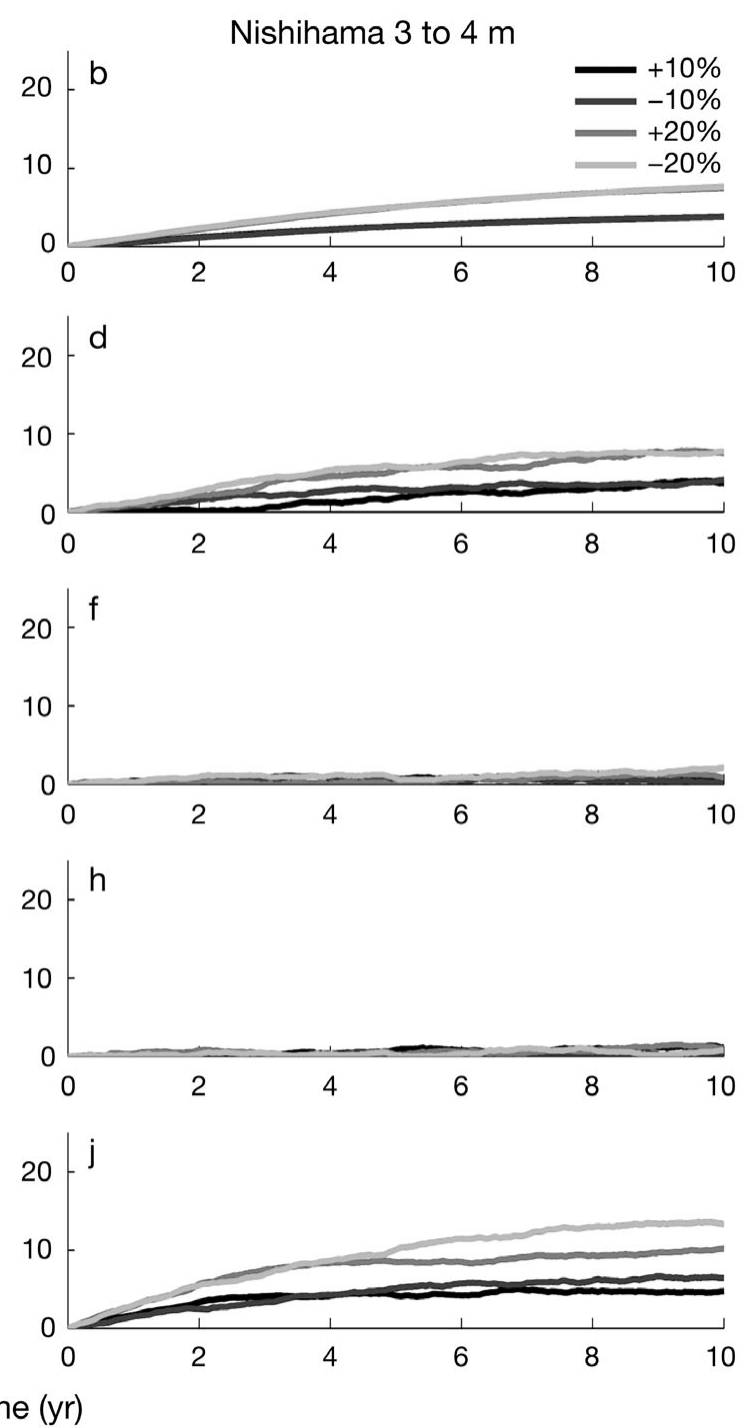

Fig. 9. Sensitivity analyses that used percent change from the original model output of the 5 vital processes for the 1996-1997 rates of $(a, c, e, g, i)$ Kushibaru and $(b, d, f, h, j)$ Nishihama at 3 to $4 \mathrm{~m}$. All other depths and rates revealed a similar pattern making mortality the most sensitive process. $(\mathrm{a}, \mathrm{b})$ recruitment, $(\mathrm{c}, \mathrm{d})$ post-settlement mortality, $(\mathrm{e}, \mathrm{f}) \mathrm{growth},(\mathrm{g}, \mathrm{h})$ partial mortality, $(i, j)$ mortality 
Nakamura \& van Woesik 2001, Bena \& van Woesik 2004). The present study examined corals subjected to a $+1.8^{\circ} \mathrm{C}$ thermal anomaly for an extended period (Nadaoka et al. 2001; Fig. 2), and showed that the sizefrequency distribution narrowed and the mean shifted toward slightly larger colonies. Here we found that $\sim 40 \%$ of the colonies in the smallest size class $(0.1$ to $10 \mathrm{~cm}$ ) died as a result of the thermal anomaly, which was largely compensated for Acropora recruitment, particularly at Kushibaru, the windward site. By contrast, Nishihama, the leeward site, seemed most affected by the warming event, showing high mortality and low recruitment rates at all depths.

The present study found that moderate temperature increases $\left(+1.8^{\circ} \mathrm{C}\right.$ above the seasonal average) shifted distributions towards larger mean colony lengths. Similarly, degradation of the physical environment can differentially select against new recruits and young corals, driving the population to old growth stages, resulting in left-skewed size-frequency distributions (Bak \& Meesters 1999, Done 1999, Edmunds 2008). Therefore, depending on the disturbance type, sizefrequency distributions may be squeezed simultaneously both from the left and the right, causing reduced variance of the population and, hence, greater vulnerability to further environmental change (Fong \& Glynn 1998, Done 1999, Loya et al. 2001, Edmunds \& Elahi 2007).

We hypothesized that (1) the $+1.8^{\circ} \mathrm{C}$ thermal anomaly on Aka Jima would shift the size-frequency distribution in the same right-skewed direction as the $-3^{\circ} \mathrm{C}$ temperature anomaly, (2) the thermal anomaly affected the population process sensitivities differently than in nonthermal anomaly years, (3) mortality rates were most influential throughout the study period and independent of the thermal anomaly and (4) recruitment was reduced after the thermal anomaly. The first hypothesis was rejected because the size-frequency shift was clearly different and dependent on thermal intensity. Hypotheses 2 to 4, however, were supported by the results in the present study. Mortality was the most sensitive process throughout, but the thermal anomaly shifted the burden of recovery toward recruitment. Yet compensation of loss by recruitment was only apparent on the windward reef (Kushibaru), and not on the leeward reef (Nishihama).

Recruitment limitation was only apparent at Nishihama for 3 yr following the thermal anomaly. Our sensitivity analyses agreed, in part, with studies on the Great Barrier Reef (Tanner et al. 1996) that showed differential mortality was a major driver of coralpopulation dynamics, but differential recruitment and postsettlement mortality processes were also important in the present study. Therefore, we have moved away from simply adopting 'supply-side ecology' to reef corals (as systems driven solely by differential recruitment events) because environmental drivers also matter (Anthony \& Connolly 2004, Hoogenboom \& Connolly 2009), especially in a warming ocean where thermal stress has recently become more intense and frequent (Thompson \& van Woesik 2009).

Considerable research effort has recently focused on understanding the ability of coral reefs to absorb such disturbances by maintaining key processes and functions, thereby resisting shifts to alternate, less desired states (Bellwood et al. 2004, Mumby et al. 2006). An understanding of disturbance thresholds, or the amount of disturbance systems can absorb, before they change states has become a central theoretical (Scheffer et al. 2001, Scheffer \& Carpenter 2003, van Nes \& Scheffer 2007) and pragmatic (Mumby et al. 2006) undertaking. The present study added to this understanding and provided the following insights: (1) recruitment was reduced after a thermal stress event and remained suppressed for many years, at least in some stations, (2) increased colony growth did not necessarily represent a lack of thermal stress, (3) the frequency of partial mortality estimates were not good indicators of corymbose Acropora population stress, (4) a log-normal distribution represented an undisturbed corymbose Acropora population, whereas a change toward a narrower sizefrequency distribution indicated recent stress and (5) in combination these criteria predicted the likelihood of population survival.

Understanding the nuances of population processes and having a quantitative baseline will allow regional comparisons and provide local managers with a set of benchmarks by which to judge effective management strategies that will increase the chance of coral success. Focusing management strategies on maintaining key processes will increase the capacity of reef systems to absorb disturbances, which lends hope to the survival of future reef systems in a rapidly warming Pacific Ocean.

Acknowledgements. Our sincere thanks extend to the staff and faculty of Aka Jima research station, particularly M. Omori, S. Hosaka, K. Shimoike and K. Iwao, for support throughout the field work period and for providing access to the temperature data (Fig. 2). We extend special thanks to J. Roth for programming assistance and to J. Gilner and J. Gulbranson for assistance with identification of coral photographs. We particularly thank S. van Woesik for producing Fig. 1, invaluable field assistance through the years and editorial comments on the manuscript. We also thank the 6 external reviewers who allowed us to clarify various aspects of our work. L. Roth was supported by a Graduate Teaching Fellowship from the National Science Foundation (Florida Tech InSTEP Program) under grant nos. DGE 0440529 and 0638702. This is contribution no. 34 from the Institute for Research on Global Climate Change at the Florida Institute of Technology. 


\section{LITERATURE CITED}

Anthony KR, Connolly SR (2004) Environmental limits to growth: physiological niche boundaries of corals along turbidity-light gradients. Oecologia 141:373-384

Babcock RC (1991) Comparative demography of three species of scleractinian corals using age- and size-dependent classifications. Ecol Monogr 61:225-244

Bak RP, Meesters EH (1998) Coral population structure: the hidden information of colony size-frequency distributions. Mar Ecol Prog Ser 162:301-306

Bak RP, Meesters EH (1999) Population structure as a response of coral communities to global change. Am Zool 39:56-65

Bellwood DR, Hughes TP, Folke C, Nystrom M (2004) Confronting the coral reef crisis. Nature 429:827-833

Bena C, van Woesik R (2004) The impact of two bleaching events on the survival of small coral colonies (Okinawa, Japan). Bull Mar Sci 75:115-126

Birkeland C (1977) The importance of rate of biomass accumulation in early successional stages of benthic communities to the survival of coral recruits. In: Taylor DL (ed) Proc 3rd Int Coral Reef Symp, Miami, 1:15-21

Caswell H (2001) Matrix population models: construction, analysis, and interpretation, 2nd edn. Sinauer Associates, Sunderland, MA

Connolly SR, Hughes TP, Bellwood DR, Karlson RH (2005) Community structure of corals and reef fishes as multiple scales. Science 309:1363-1365

Doherty P, Fowler T (1994) An empirical test of recruitment limitation in a coral reef fish. Science 263:935-939

> Done TJ (1988) Simulation of recovery of pre-disturbance size structure in populations of Porites spp. damaged by the crown of thorns starfish Acanthaster planci. Mar Biol 100: $51-61$

Done TJ (1999) Coral community adaptability to environmental change at the scales of regions, reefs, and reef zones. Am Zool 39:66-79

> Dornelas M, Connolly SR, Hughes TP (2006) Coral reef diversity refutes the neutral theory of biodiversity. Nature 440: 80-82

Edmunds PJ (1994) Evidence that reef-wide patterns of coral bleaching may be the result of the distribution of bleaching-susceptible clones. Mar Biol 121:137-142

Edmunds PJ (2008) The effects of temperature on the growth of juvenile scleractinian corals. Mar Biol 154:153-162

Edmunds PJ, Elahi R (2007) The demographics of a 15-year decline in cover of the Caribbean reef coral Montastraea annularis. Ecol Monogr 77:3-18

Fong P, Glynn PW (1998) A dynamic size-structured population model: Does disturbance control size structure of a population of the massive coral Gardineroseris planulata in the Eastern Pacific? Mar Biol 130:663-674

- Guttal V, Jayaprakash C (2008) Changing skewness: an early warning signal of regime shifts in ecosystems. Ecol Lett 11:450-460

Holt RD (2009) Bringing the Hutchinsonian niche into the 21st century: ecological and evolutionary perspectives. Proc Natl Acad Sci USA 106:19659-19665

Hoogenboom MO, Connolly SR (2009) Defining fundamental niche dimensions of corals: synergistic effects of colony size, light, and flow. Ecology 90:767-780

Hubbell SP (1997) A unified theory of biogeography and relative species abundance and its application to tropical rain forests and coral reefs. Coral Reefs 16(Suppl): S9-S21

> Hughes TP, Jackson JB (1985) Population dynamics and life histories of foliaceous corals. Ecol Monogr 55:141-166
Hutchinson GE (1978) An introduction to population ecology. Yale University Press, New Haven, CT

IPCC (Intergovernmental Panel on Climate Change) (2007) Climate change 2007: synthesis report. Pachauri RK, Reisinger A (eds) Contribution of working groups I, II and III to the fourth assessment report of the Intergovernmental Panel on Climate Change. IPCC, Geneva

Karlson RH, Cornell HV, Hughes TP (2004) Coral communities are regionally enriched along an oceanic biodiversity gradient. Nature 429:867-870

> Keough MJ, Downes BJ (1982) Recruitment of marine invertebrates: the role of active larval choices and early mortality. Oecologia 54:348-352

- Lasker HR (1990) Clonal propagation and population dynamics of a gorgonian coral. Ecology 71:1578-1589

Lasker HR, Coffroth MA (1999) Responses of clonal reef taxa to environmental change. Am Zool 39:92-103

$>$ Lefkovitch LP (1965) The study of population growth in organisms grouped by stages. Biometrics 21:1-18

> Loya Y, Sakai K, Yamazato K, Nakano Y, Sambali H, van Woesik R (2001) Coral bleaching: the winners and the losers. Ecol Lett 4:122-131

> Mumby PJ, Dahlgren CP, Harborne AR, Kappel CV and others (2006) Fishing, trophic cascades, and the process of grazing on coral reefs. Science 311:98-101

Nadaoka K, Nihei Y, Wakaki K, Kumano R and others (2001) Regional variation of water temperature around Okinawa coasts and its relationship to offshore thermal environments and coral bleaching. Coral Reefs 20:373-384

- Nakamura T, van Woesik R (2001) Water-flow rates and passive diffusion partially explain differential survival of corals during the 1998 bleaching event. Mar Ecol Prog Ser 212:301-304

Pandolfi JM (2002) Coral community dynamics at multiple scales. Coral Reefs 21:13-23

> Pechenik JA (1999) On the advantages and disadvantages of larval stages in benthic marine invertebrate life cycles. Mar Ecol Prog Ser 177:269-297

> Rinkevich B, Loya Y (1986) Senescence and dying signals in a reef building coral. Experientia 42:320-322

Scheffer M, Carpenter SR (2003) Catastrophic regime shifts in ecosystems: linking theory to observation. Trends Ecol Evol 18:648-656

Scheffer M, van Nes EH (2006) Self-organized similarity, the evolutionary emergence of groups of similar species. Proc Natl Acad Sci USA 103:6230-6235

Scheffer M, Carpenter S, Foley JA, Folke C, Walker B (2001) Catastrophic shifts in ecosystems. Nature 413:591-596

Scheirer CJ, Ray WS, Hare N (1976) The analysis of ranked data derived from completely randomized factorial designs. Biometrics 32:429-434

> Shampine LF, Reichelt MW (1997) The MATLAB ODE suite. SIAM J Sci Comput 18:1-22

- Tanner JE, Hughes TP, Connell JE (1994) Species coexistence, keystone species, and succession: a sensitivity analysis. Ecology 75:2204-2219

Tanner JE, Hughes TP, Connell JE (1996) The role of history in community dynamics: a modelling approach. Ecology 77:108-117

Thompson DM, van Woesik R (2009) Corals escape bleaching in regions that recently and historically experienced frequent thermal stress. Proc R Soc B Biol Sci 276:2893-2901

Underwood AJ, Fairweather PG (1989) Supply-side ecology and benthic marine assemblages. Trends Ecol Evol 4: $16-20$

Underwood AJ, Keough MJ (2001) Supply-side ecology: the nature and consequences of variations in recruitment of 
intertidal organisms. In: Bertness MD, Gaines SD, Hay ME (eds) Marine community ecology. Sinauer Associates, Sunderland, MA, p 183-200

van Nes EH, Scheffer M (2007) Slow recovery from perturbations as a generic indicator of a nearby catastrophic shift. Am Nat 169:738-747

van Woesik R (2002) Processes regulating coral communities. Comment Theor Biol 7:201-214

> van Woesik R (2010) Calm before the spawn: global coral spawning patterns are explained by regional wind fields. Proc R Soc B Biol Sci 277:715-722

van Woesik R, Done TJ (1997) Coral communities and reef growth in the southern Great Barrier Reef. Coral Reefs 16:103-115

Vermeij MJ, Sandin SA (2008) Density-dependent settlement

Editorial responsibility: Charles Birkeland,

Honolulu, Hawaii, USA and mortality structure the earliest life phases of a coralpopulation. Ecology 89:1994-2004

Veron JEN (1992) Hermatypic corals of Japan, 1st edn. Australian Institute of Marine Science, Cape Ferguson

Wallace C (1999) Staghorn corals of the world: a revision of the coral genus Acropora (Scleractinia; Astrocoeniina; Acroporidae) worldwide, with emphasis on morphology, phylogeny and biogeography. CSIRO publishing, Collingwood

Webster PJ, Holland GJ, Curry JA, Chang HR (2005) Changes in tropical cyclone number, duration, and intensity in a warming environment. Science 309:1844-1846

Zvuloni A, Artzy-Randrup Y, Stone L, van Woesik R, Loya Y (2008) Ecological size-frequency distributions: how to prevent and correct biases in spatial sampling. Limnol Oceanogr Methods 6:144-152

Submitted: January 8, 2010; Accepted: April 27, 2010

Proofs received from author(s): July 18, 2010 